The leader of the experimental herd has now been in Scotland four and a half years. After setbacks on unsuitable land, the herd has been increasing since May 1955, through calves bred and born in the Cairngorms, and now numbers sixteen. When considering the future of reindeer in Scotland, it is recognized that there is some overlap between the pasture of reindeer, red deer and sheep. But, as there are areas in Scotland which are scarcely grazed by red deer or sheep and yet offer good reindeer pasture, this slight overlap would not justify the exclusion of reindeer.

\section{RARER BIRDS OF PREY}

$\mathrm{B}^{\mathrm{I}}$ RDS of prey always attract attention and arouse an unusual degree of admiration or per. secution according to outlook. Largely for that reason, their distribution and their breeding-populations are often shrouded in secrecy. Indiscriminate disclosure which could lead to persecution or disturbance of hard-pressed species would be indefensible. Secrecy can be carried too far, however, and it is essential to both science and bird-protection that adequate records should be kept, and that information which cannot harm the birds should be shared. The editors of British Birds have, therefore, prepared an up-to-date account of British birds of prey, indicating those factors which have been working for and against the birds (50, No. 4 ; April 1957).

Over the past few years there has been an increase in the numbers of buzzards, kites, hen harriers, marsh harriers and, perhaps, golden eagles. The osprey may now be re-establishing itself, and the goshawk has returned after an absence of a century or two. In almost every case, however, the position to-day looks worse than it was a year or two ago. The buzzard received a severe setback during 195455 through the impact of myxomatosis, coupled with increased human persecution. The kite population has also been unsettled and reduced. The 1956 reports from Scotland indicate that the hen harrier fared badly on the mainland and in the Hebrides. The golden eagle also suffered from shooting, poisoning, eyrie-stoning and burning, and in 1956 a number of pairs were missing from regular haunts. The disturbance caused by human intervention during the osprey's attempted nesting last season is widely known. Marsh harriers failed almost entirely in $\mathbf{1 9 5 6}$ in one of their three strongholds. No breeding record of the goshawk has been made in recent seasons. Of other birds of prey, the numbers of Montagu's harrier are perhaps about the same as before the War, or a little higher, although probably less than they were ten years ago ; there is no evidence of ehange in the status of hobby or honey buzzard; the peregrine has made some recovery from war-time organized. shootings.

It is hoped that the publication of the survey will lead to the filling in of a number of gaps in the avail. able information by contributions from other ornithologists. It is also hoped that efforts will be made to review the food and economic status of birds of prey and to bring about a more scientific and modern attitude towards them. A special article on the buzzard is being prepared for a later issue of the journal.

\section{A NEW ELECTRONIC DIGITAL COMPUTER}

$\mathrm{T}$ HE Metropolitan-Vickers Electrical Co., Ltd. which has for some years been engaged on basic developments for a variety of electronic computers, has recently announced the completed development of the first model of a new range, the 'Metrovick 950', which is a general-purpose electronic digital computer capable of application to a wide variety of mathematical problems in research and engineering design. The computer incorporates interesting features of modern technique including the use of printed wiring on the plug-in boards and the extensive use of transistors in place of thermionic valves.

The machine is basically $a_{0}$ device which will do arithmetic at high speed under the control of instructions given to it by the operator. The problem to be solved must first be stated in mathematical terms, and then the process of solution must be reduced to a series of simple arithmetical operations which the machine will perform. The list of instructions, called the 'programme', causes the machine to perform the necessary operations and combines them in appropriate sequence. The five basic units of the computer consist of the input equipment, for feeding information into the machine; the store, for holding instructions and data; arithmetical circuits, for performing the calculations; output equipment, for giving the results; and a control unit, to co-ordinate the whole machine so that instructions are obeyed correctly and in the right order. The input of numerical data and the programme of instructions are coded into holes punched on a paper tape, which is fed into the computer and from there read off photoelectrically at a high speed of up to 200 characters per second. The numbers are punched in the tape as decimals, each digit being represented by a fivehole combination, and each instruction is coded as a combination of decimal digits which is punched into the tape in that form. The computer automatically converts the decimal form into a binary representation in which one number or instruction is normally represented by thirty-two binary digits, called a 'word'. The main store is a cylindrical drum coated with magnetic oxide, on which a total of 4,096 'words' are 'written' as magnetized spots on 128 separate circumferential tracks, and the mean access time to the location of any word on the drum is one-half of a revolution period, that is, ten milliseconds. In the circuits the numbers and instructions are represented by electrical impulses which occur in a regular series with a pulse or digit frequency of $75 \mathrm{kc} / \mathrm{s}$. In addition to the main store there are several stores with capacities of one or two words, the 'registers', for use in the arithmetical unit. The registers take the form of regenerative tracks on the drum, and a further store holding eight words on a regenerative track is provided to enable instructions to be modified after they are taken from the main store and before they are obeyed. The arithmetical circuits, which use transistors, include an addersubtractor unit and a multiplier. The output is by means of five-hole punched tape or a printed page, and the control unit, using transistor circuits, controls the sequence of operations and the flow of instructions and numbers in the computer. The basic timing of the computer is controlled by signals obtained from the tracks on the magnetic drum, thus synchronizing the computer with the drum. 